\title{
Differences in Mode of Classroom Instruction Between China and the United States
}

\author{
Yuze Liang ${ }^{1, \mathrm{a}, *, \dagger}$ Yuyuan Ren ${ }^{2, \mathrm{~b},{ }^{,}, \dagger}$ Yue $\mathrm{Wu}^{3, \mathrm{c}, *, \dagger}$ \\ ${ }^{1}$ School of International Education Cooperation, Tianjin University of Commerce, Tianjin, Tianjin (300000), China \\ ${ }^{2}$ School of Foreign Languages, Sichuan University of Science and Engineering, Yibin City, Sichuan Province (644000), \\ China \\ ${ }^{3}$ School of Geography and Tourism, Anhui Normal University, Wuhu City, Anhui Province (241002), China

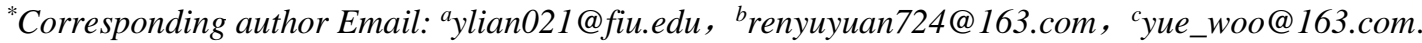 \\ These authors contributed equally.
}

\begin{abstract}
Mode of classroom instruction is an important aspect of education, which serves as the main position of applying educational theories into practice. Therefore, exploring efficient and high-quality teaching mode actively has become one of the important topics for educators. With the increasing educational exchanges between China and foreign countries, the mode of classroom instruction of Chinese and foreign countries has attracted more and more attention. This paper focuses on the differences between Chinese and U.S.'s education and compares the methods, teacher-student relationships and evaluation methods between the two countries. Afterward, the differences between in school's mode of classroom instruction as well as advantages and disadvantages are analyzed respectively, Finally, we look forward to the future development of education. Although the mode of classroom instruction of Chinese and American have their own benefits and drawbacks, they should learn from each other to jointly promote the continuous improvement of education. These results shed light for the improvement of teaching instruction and the development of education.
\end{abstract}

Keywords: Mode of classroom instruction, Teaching methods, Teacher-student relationship, Teaching evaluation methods.

\section{INTRODUCTION}

Classroom teaching is closely related to every student, which affects students' attitude towards study, interpersonal relationship with related personnel and future ability development directly or indirectly. China and the U.S., as major countries in education, have distinctive characteristics in curriculum teaching, which has led many scholars to conduct comparative studies in this field. Generally speaking, China is more inclined to adopt cramming teaching method, which focuses on the cultivation of students' basic knowledge and is committed to build a relatively integrated knowledge system. In contrast, U.S. prefers to adopt heuristic teaching method, which can fully promote the development of students' personality through different teaching forms and cultivate students' innovation and dialectical thinking ability. During class interaction between teachers and students, Chinese students tend to be more introverted and express statements are based on their respect for teachers. On the contrary, in American classrooms, students is more frequent and the atmosphere is hotter. It is easier for teachers and students to establish a close relationship. These differences can be ascribed to the ideological and cultural differences between China and the United States. In terms of teaching evaluation, China still focuses on examination results, while the evaluation methods are more diverse in the United States, which require not only academic achievements but also individual comprehensive abilities.

\section{THE DIFFERENCES OF TEACHING METHODS BETWEEN CHINA AND THE UNITED STATES}

\subsection{Differences in Teaching Objectives}

Compared with western teaching, the education system in China focuses on foundational knowledge in disciplines. For a long time, China's education has been cultivating students' respect for knowledge, paying attention to students' construction and mastery of 
knowledge system and emphasizing students' memory, imitation and repetition of knowledge as well as their problem-solving skills $[1,2]$. This teaching method, which attaches importance to the logic and structure of the discipline itself, help students build relative integrated knowledge systems and deepen their understanding of teacher imparted knowledge through repeated practices in some extent. However, it is easy to ignore students' abilities to analyze and solve problems in real life. Meanwhile, Chinese curriculum goals emphasize the cultivation of foundational knowledge due to the implementation of the college entrance examination policy. In this case, a number of schools and teachers may pay too much attention to the teaching of foundational knowledge, blindly pursue high graduation rates and ignore the real connotation of quality-oriented education on account of their utilitarian thoughts $[2,3]$. Some of China's schools are known as "super middle schools", namely regular schools with large scale, strict management and high enrollment rates, which are also controversial [4]. Some people believe that these schools enable more students to enjoy high-quality educational resources, while others hold the view that they are the product of the education evaluation system that pursues graduation rates as the goal and the result of local government's one-sided pursuit of educational achievements [4]. Emphasis on students' mastery of foundational knowledge and enrollment rate is useful to some extent. Nevertheless, students should not only focus most of their energy on attending lectures and doing exercises, but also cultivate their ability of critical thinking and innovation.

On the other hand, the American education system is based on students' competency, i.e., American schools pay more attention to students' questioning, criticism, exploration and innovation of knowledge as well as the ability to comprehensively use knowledge [1]. The U.S. has formed its own curriculum theory and practice system, which is characterized by strengthening the connection between the curriculum and life, which gives full consideration to the diversity of students' backgrounds and interests [3]. This mode of education is aimed at students' practical ability and helps students better apply knowledge to work and life, which needs to be learned by China. Meanwhile, there has been an obvious trend in the classroom teaching reform in American colleges and universities. Specifically, it helps each student develop the maximum potential in learning and to advocate "example teaching method", "interactive teaching" and "group cooperative learning" [5]. The combination of different teaching modes can improve students' abilities of independent learning, continuous exploration of knowledge and teamwork, which is also conducive to better achieving teaching objectives.

\subsection{Differences of Students' Class Participation and Teachers' Teaching Style}

In China, the cramming teaching method is widely adopted and students are more passive and less involved in class. This teaching method has a subconscious premise that students are considered to be ignorant of the knowledge that they are going to learn and teachers need to teach and indoctrinate them in order to provide them with a complete knowledge system, which places special emphasis on the basic concepts [6]. If teachers only teach the knowledge and students passively accept the knowledge, then the students may not be highly motivated to participate in the class and their efficiency of receiving knowledge may also be low. In the meantime, Chinese classroom teaching advocates that teachers should play a leading role, which requires teachers to guide and organize students in the teaching process [2]. If teachers can not properly play their roles in the classroom, it is likely to reduce students' learning motivation and opportunities. In terms of teaching content, teachers will prepare lessons together, carry out teaching and research group activities, systematically explain each chapter and each concept in strict accordance with the unified outline, arrange the course schedule in the same way and measure the teaching quality of teachers in accordance with the classroom teaching standards $[6,7]$. Unified syllabuses and course schedules can guarantee the overall quality of teaching, but it is difficult for teachers to innovate and students may lack the motivation for learning and time for independent thinking. In addition, Chinese teachers pay attention to exercises after class and require students to master and consolidate the teaching content through repeated exercises of homework [3]. Although exercises can help students master the knowledge of what they have learned, they get bored and dull easily, i.e., reduces their learning enthusiasm.

On the other hand, heuristic teaching method is adopted in the United States and students are more active with the high degree of participation in class. The curriculum atmosphere of heuristic teaching is relatively relaxing. The premise of this method is that students have certain self-learning abilities and some basic understandings of the knowledge introduced in the courses [6]. On this basis, students will better exert their learning motivation and actively participate in class, while teachers can timely understand students' problems. In the teaching process, students often play dominant roles and the importance of communication is emphasized. Teachers always put the idea of personalized learning through the class, encourage students to think and explore constantly and respect students' individual differences [2, 7]. Meanwhile, teachers work independently in classroom teaching without considering what other schools or teachers do [7]. Student-centered teaching can help students develop 
potential, cultivate critical thinking ability and strengthen the interaction between students and teachers. However, this method also needs to be modest. If the overall atmosphere is too loose and casual, students may be too self-centered and neglect classroom discipline. Besides, American teachers pay attention to the effectiveness of teaching, which requires students to do more preparation before and after class, read the relevant chapters in the main textbook and other auxiliary readings intensively [3, 6]. A large number of reading materials may bring a greater study burden to students. However, students can cultivate the ability of independent thinking, better interact with their teachers in class and improve the efficiency of learning through these materials.

\section{THE DIFFERENCES OF TEACHER- STUDENT RELATIONSHIP BETWEEN CHINA AND THE UNITED STATES}

Teacher-student relationship means that teachers and students form a special bond in the education process, including both working relationships during the class and interpersonal relationships and psychological relationships after class in order to boost mutual development [8].

\subsection{The Importance of Teacher-Student Relationship}

Teacher-student relationship is considered as one of the most common and essential relationships in school, which exerts enormous impacts on the process of education. $\mathrm{Hu}$ argues that teacher-student relationship can affect both teaching and learning process [9]. Chen refers that teaching and learning process can promote each other by harmonious teacher-student relationships [10]. Yao emphasizes that teacher-student relationship plays an important role for students and teachers, which directly affects the effectiveness of teaching and learning as well as the communication between teachers and students [11]. From the student's perspective, harmonious teacher-student relationship can enable them to get more interested in relevant subject. Therefore, they will have more active attitude towards the class and participate more in class activities. Through this way, they can also gain much better achievement. Form the teacher's prospective, especially for those young teachers who just start their teaching careers, being accepted by their students will inspire them to become more confident. Thus, they will teach their students with more zeal and attempt to achieve better teaching outcomes. Based on above analysis, successful teacher-student relationship can greatly promote the educational outcomes.

\subsection{Comparison on the Teacher-Student Relationship between China and the United States}

\subsubsection{Chinese teacher-student relationship}

Chinese teacher-student relationship is often based on respect. For Chinese students, they are taught to respect teachers since their childhood. Ma holds the view that Chinese students are supposed to sit up straight in class [12]. Besides, they should raise hands if they want to ask some questions and teachers are regarded as the definite authority above all students. Zhang points that in Chinese classrooms, students wait for questions from the teacher, rarely ask or interrupt the teacher, and fear arguing with the teacher [13]. It is common to see the phenomenon that students keep silent and take notes seriously while the teacher talk mostly in Chinese classroom since it is impolite and improper for students to interrupt teachers while they are taking. Although currently the new curriculum policy has conducted to ensure the students' subject statues in the process of schooling, most of them still have little intention to speak out during the class. If they have something confusing, even though teachers leave time to answer their questions in class, they prefer to ask teachers privately after class. Besides, they should greet teachers politely if students come across their teachers after class. Sun points out that sometimes if students meet their teachers outside the classroom, they will subconsciously conceal themselves from teachers [14]. Therefore, Chinese teacher-student relationship is usually on the straight and narrow.

\subsubsection{American teacher student relationship}

In Contrast, American teacher-student relationship tends to be more relaxing and closer. For America students, they have more freedom during the class. Sun also points out that teacher-student relationship in the US is always democratic, equal, intimate and friendly whether in or out of class [14]. He refers that the teacher and students often sit in a circle during the class. Teachers can sit at the desk or on the floor, while students also sit disorderly. At the same time, students can raise an objection anytime if they have questions about their teachers' opinions. Probably, they will then have a heated discussion, and teachers will suppose their critical thinking and classroom performance are excellent [14]. Additionally, the American teacher-student relationship become more casual out of class. American teachers and students are friends, i.e., students can directly call the first name or nicknames of their teachers. Their teachers will never mind and give a friendly response [12]. However, the behavior of teachers and students are inevitably a bit loose lacking of discipline [15]. Thus, American teacherstudent relationship is usually more liberal but disengaged sometimes. 


\subsubsection{Reasons for the Differences between Chinese and American Teacher-Student Relationship}

The differences between Chinese and American teacher-student relationship main result from the cultural differences between the two countries. Chen suggests that Chinese education has been influenced by Confucianism and Taoism for thousands of years. Although Chinese education has undergone many reforms, the feudal ideology of obedience still has a great effect on it [16]. Respecting teachers is one of the traditional virtues of China over the years. Chen also states that in this type of society atmosphere, teachers become the masters of the class, i.e., students are willing to believe in their teachers and become meek naturally [16]. In contrast, America is a multicultural country. Ma states that individualism is a major part of American culture. On account of this, American students are encouraged to be independent from an early age, e.g., make decisions by themselves and express their own opinions [15]. Thus, teachers and students are equal and students have more passionate to participate in American class.

In conclusion, as to teacher-student relationship, China and America can learn from each other. As Chinese teachers, they should respect students as well and become their mentors. With regard to American teachers, they should set some class rules to cultivate students' sense of discipline. By this way, teachers will be more possible to provide a more democratic, friendly, and harmonious classroom atmosphere.

\section{THE DIFFERENCE OF TEACHING EVALUATION METHODS BETWEEN CHINA AND THE UNITED STATES}

\subsection{Teaching Evaluation Methods in China}

\subsubsection{Introducing teaching evaluation methods in China}

One of the most significant characteristics of students' academic evaluation in China is that all kinds of external summative evaluation occupy the absolute dominant position [17]. For most schools, especially primary and middle schools, the exam-oriented education mode is still popular, which leads to the dominance of some summative evaluation methods (e.g., mid-term examination and final examination). Examination is still the most important measurement to assess students' performance. At present, most colleges and universities in China conduct comprehensive evaluation on students' classroom performance and practical activities in the teaching process, but the proportion of examination results at the end of the semester is still large. Most schools generally take students' final examination results as the most important criterion to measure the course learning performance [18]

\subsubsection{Advantages and disadvantages of teaching evaluation in China}

This evaluation model based on examination results can quantify the learning effect of students and increase the visualization of teaching results. Moreover, this way of assessment ensures the fairness and justice of the evaluation results to a certain extent. Considering stresses human feelings and relations in China, the only basis for evaluation is the unified and strict score standard, which greatly reduces the intervention of power in this field and ensures the fairness of education to a certain extent [17].

Inevitably, this relatively single evaluation method has many disadvantages in teaching. In education, this kind of assessment emphasizes the standard of everything, teachers and students have become the vassal of the examination, lack of independence and flexibility [19]. Besides, the examination-oriented education model is false in educational effect to some extent. Because of the utilitarian purpose of education, teachers cram education for students in terms of the knowledge that should be summed up by students themselves in order to compress the time, which also highlights the speculative nature of education [19]. Moreover, external large-scale standardized examinations are usually carried out at the end of the semester, i.e., the feedback of students' evaluation information is lagging, which often delays the best time to improve students' learning [17].

\subsection{Teaching Evaluation Methods in the United States}

\subsubsection{Introducing teaching evaluation methods in the United States}

American schools are relatively diversified in terms of teaching evaluation and pay more attention to process evaluation. Taking the admission standards of American universities as an example, the admission standards of American universities are quite complicated. The high school scores and standard examination scores, e.g., SAT, $\mathrm{AP}$, etc., are the first factors to be considered in the admission of famous universities. Then, there are outstanding leadership skills. Priority is given to those with outstanding academic achievements, e.g., Olympic Mathematics champion, Westinghouse Science Prize winner, etc. After these admission conditions, $60 \%$ to $70 \%$ of the total enrolment has been selected. The rest of the admission mainly depends on Teachers' recommendation letters and applicants' compositions. By reading the applicants' compositions, the selectors can see the students' writing level, personality, passion, leadership, determination and integrity [20]. 


\subsubsection{Advantages and disadvantages of teaching evaluation in the United States}

This kind of teaching evaluation method does not take achievement as the only evaluation index, it tests students' comprehensive ability in many aspects. In the meantime, the evaluation index is distributed in all stages of students' learning, which is helpful for teachers to find students' problems and correct them in time and it will not bring too much learning pressure to students [21]. In addition, this evaluation method can promote the development of students' comprehensive abilities (e.g., leadership and creativity), which is conducive to students' personalized development.

However, this kind of teaching evaluation method also has some drawbacks. This kind of diversified process evaluation usually has strong subjectivity and no clear standard. Therefore, it cannot meet the requirements of professional students' evaluation method in the aspects of scientificity, fairness and rationality [22]. Besides, focus on the way of process evaluation, it is difficult to investigate the psychological quality and pressure state of students in the examination ignoring the summative evaluation of students. Moreover, the evaluation content of this evaluation method is various, which increases the difficulty of evaluation to a certain extent. It costs a lot of human, material and financial resources, but the value of the evaluation results is limited [22]. These are the problems that are easy to arise in the process of American education evaluation.

\subsection{The Future Development of Teaching Evaluation Methods}

Any evaluation method has its own advantages and disadvantages for the development of students. The purpose of teaching evaluation should be based on the principle of promoting students' all-round development and personality development, seeking common ground while reserving differences to achieve the comprehensive development of students' quality. The Chinese Ministry of education's "notice on actively promoting the evaluation and examination system in primary and middle schools" points out that "it is necessary to study and formulate scientific, simple and easy evaluation methods that are convenient for evaluators and explore evaluation methods that are conducive to guiding students, teachers and schools to conduct positive selfevaluation and other evaluation." [23]. In this case, we should optimize the form of evaluation, choose reasonable and scientific examination methods in the process of teaching evaluation according to the characteristics of curriculum content and students' personality [23]. For the future development direction of education, educators should change the traditional evaluation concept and establish the evaluation concept of development education with students' improvement as the center [24]. The approach of education evaluation should pay attention to respecting students' personality. Meanwhile, it should be based on improving students' knowledge and ability. The evaluation and the learning process interact with each other. In the learning process, the evaluation feedback is continuously carried out, and the joint participation of the evaluator and the evaluated is strengthened to build a learning oriented and perfect evaluation system.

\section{CONCLUSION}

In summary, this paper reviews the differences in mode of classroom instruction between China and the United States. Firstly, the differences of teaching methods based on teaching objectives, students' participation, and forms of teaching are introduced. Subsequently, the differences of teacher-student relationship and the importance of them as well as the reasons discussed. Lastly, we review the differences of teaching evaluation methods and summarize the future development of it. According to our results, the differences between these two countries education is attributed to their unique tradition and culture. For China and America, both countries' teaching models have their own pros and cons. For the common progress, China and America should draw on the merits from each other to improve their educational levels. For Chinese education, they should gradually abandon the exam-oriented education and make efforts to develop the qualityoriented education. With regard to American education, they should set clear educational standards to regulate the classroom discipline and enhance the quality of education. This review generalizes the importance to compare the difference among different countries' education and inspires future researchers to find out the methods for the education modes.

\section{REFERENCES}

[1] Y.C. Shu. (2020). A comparative study on classroom teaching methods of Chinese and American universities to help Chinese institutions of higher learning develop into "first-class universities of the world". Journal of Higher Education (08), 20 22.

[2] Y.L. Qiu \& G.Q. Li. (2013). A comparative study of classroom teaching between China and America. Education and Teaching Forum (29), 163164.

[3] H.L. Dong. (2008). The comparison and cultural origin of curriculum teaching methods between Chinese and American universities. Education and Career (14), 67-68.

[4] H.Z. Tian, D. Wang \& J.H. Jiang. (2016). An instit utional logic analysis of the phenomenon and evolu 
tion of "super high school". Education and Econom y (05), 3-11.

[5] M.N. Zhao. (2004). Three typical instructional mod els in U.S. higher education classrooms. Comparati ve Education Review (04),11-15

[6] H. Zhen. (2007). Comparative research on classroom teaching in universities between China and USA. Higher Education Development and Evaluation (02), 106-111+124.

[7] F. Yang. (2010). Classroom teaching under the influence of Chinese and American cultural differences. Journal of Changchun Education Institute (06), 87-88.

[8] X.H Liu. (2015). Modern Education Technology of the Relationship Build between Teachers and Students in Status and Application. (Doctoral dissertation, Henan University).

[9] X. Hu. (2012). Analysis on Status of Teacherstudent Relationship in Junior School and the Construction of Harmonious Relationship between Teachers and Students under the Background of the New Curriculum Reform. (Doctoral dissertation, Hangzhou Normal University).

[10] F.J Chen. (2014). The Research of "Mentor" Model Relationship between Teachers and Students under the View of Moral Education in University. (Doctoral dissertation, Hunan Agricultural University).

[11] Y. Yao. (2016). Study on Constructing the Harmonious Teacher-student Relationship in Middle Schools - - A case study of XX middle school in Suzhou. (Doctoral dissertation, Soochow University).

[12] B.G. Ma. (2009). Comparison of Differences in Teacher-student Relationship between Chinese and American High Schools. (Doctoral dissertation, Shandong Normal University).

[13] Q. Zhang. (2011). A Comparative Study of Classroom Culture between China and America. (Doctoral dissertation, Shandong Normal University).

[14] X.L. Sun. (2010). A Comparative Study on the Relationship between Teachers and Students in basic education between China and America. (Doctoral dissertation, Shaanxi Normal University).

[15] B.G. Ma. (2008). A Brief Analysis of the Differences between Chinese and American Teacher-student Relationship. Journal of the Party School of CPC Jinan Municipal Committee, 000(001), 51-53.
[16] Z.Y. Chen. (2012). Comparison and Reflection on the Differences between Chinese and American Classroom Teaching. Journal of Hubei University of Education (1), 117-119.

[17] S.G. Zhao. (2013). A Study on Classroom Assessment for Learning.

[18] X.M. Zhang. (2019). Analysis of Several Common Student Performance Evaluation Methods. The Guide of Science \& Education, 361(01), 175-176.

[19] X.X. Lu, J.F. Tang, X.F. Luo. (2007). Institutional analysis of exam-oriented education in China. Journal of Hubei University of economics.

[20] F. Wang. (2011). Quality evaluation standard. Research on the development of Education, (04), 1418.

[21] M. Guo. (2013) A study on the diversified admission methods of American Universities. (Doctoral dissertation, Shaanxi Normal University).

[22] B.B Xu. (2016). From comprehensive quality evaluation to core quality evaluation. (medical dissertation, East China Normal University).

[23] X.H. Guo. (2018). On the reform of academic evaluation of primary and secondary school students. Educational practice and research, 000(011), 50-52.

[24] D.D. Xu. (2016). Research on the Junior High School Students' Academic Level Evaluation under the Comprehensive Quality Evaluation Background. Hennan University. 